\title{
El héroe intelectual. La figura del poeta mártir en "La literatura es fuego" de Mario Vargas Llosa
}

\author{
Jorge Valenzuela Garcés \\ Universidad Nacional Mayor de San Marcos \\ jorgevalenzuela4@hotmail.com
}

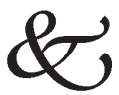

Resumen

En este artículo nos ocupamos de analizar el modo en que Mario Vargas Llosa construye, en el texto "La literatura es fuego", la imagen del héroe intelectual a partir de la vida del poeta Carlos Oquendo de Amat. El texto "La literatura es fuego", leído el 11 de agosto de 1967, en Caracas, a propósito de la concesión a Vargas Llosa del Premio Rómulo Gallegos, es uno de los más extraordinarios discursos dados por un escritor al momento de recibir un premio literario. El énfasis con el que se construye la imagen del escritor inconforme a partir del recuerdo de un poeta como Carlos Oquendo de Amat y la forma en que la literatura es presentada como una actividad crítica, corrosiva e indomeñable, convierte este discurso en una muestra del desarrollo que, entonces, el campo intelectual había alcanzado en relación a los niveles de conciencia que los escritores de la época tuvieron respecto a su propia condición, a su oficio y a sus relaciones con el poder.

Para el análisis empleamos el marco de la crítica cultural y nos centramos en las relaciones que los intelectuales, a través del ejercicio de la literatura, establecen con el poder.

Palabras claves: Mario Vargas Llosa, héroe intelectual, Carlos Oquendo de Amat, "La literatura es fuego".

\begin{abstract}
In this article we deal to analyze how Mario Vargas Llosa built, in the text "La literatura es fuego", the image of the intellectual or cultural hero from the life of poet Carlos Oquendo de Amat. The text "Literature is fire" read the August 11, 1967, in Caracas, about Vargas Llosa granting Rómulo Gallegos award, is one of the most extraordinary speeches
\end{abstract}


given by a writer upon receiving a literary award. The emphasis with which the writer builds maverick image from memory of a poet like Carlos Oquendo de Amat and how literature is presented as a critical activity, corrosive and indomitable, makes this speech in a sample of development that, then, the intellectual field had reached in relation to levels of consciousness that the writers had about their own condition, to their craft and their relations with the power.

For the analysis we use the framework of cultural criticism and focus on the relationships that intellectuals, through the practice of literature, establish with the power.

Keywords: Mario Vargas Llosa, Intellectual hero, Carlos Oquendo de Amat, "La literatura es fuego".

\section{El escritor-intelectual y la revolución en "La literatura es fue- go" de Vargas Llosa}

Una firme resistencia ideológica al poder político y económico del capitalismo norteamericano, en un contexto marcado por la existencia de gobiernos burgueses o de extrema derecha, caracteriza, en términos generales, al campo intelectual hispanoamericano de los años sesenta. Por ello, como actitud general ante la vida, la actitud antiburguesa es esencial para comprender a escritores, críticos literarios, sociólogos, antropólogos y filósofos cuyo discurso, fundado en la necesidad del cambio y de la democratización de la sociedad, construye, simultáneamente, la figura del intelectual radicalizado, figura protagónica en el proceso de consolidación de un público atento al desarrollo del arte y de la literatura. En este contexto, los escritos de Sartre y de Marcuse, representantes del discurso de la llamada nueva izquierda ${ }^{1}$, son esenciales para entender el proceder y la toma de posición de muchos de ellos.

Como ideología general, el campo intelectual vive la influencia del marxismo en sus dos vertientes: la moscovita y la maoísta, aunque el desarrollo de la experiencia viva del castrismo resulta siendo la dominante en América Latina a partir del triunfo de la Revolución Cubana (1959). De hecho, en muchas agrupaciones políticas y literarias de los sesenta, e incluso de los setenta, se vive la discrepancia entre las posiciones maoístas, que empezaban a tener una fuerte presencia después de la ruptura del monolítico Partido Comunista

1 En su momento, la llamada "Nueva izquierda", que congregó el pensamiento de Sartre, Marcuse, Fanon, y Ernesto “Che” Guevara, se constituyó en la guía de los escritores del "boom”. En su orientación, el pensamiento de la nueva izquierda se alejó de la sumisión a la línea de partido y a la obsecuencia que caracterizó a las posiciones del comunismo de inicios de siglo XX. En términos generales, el pensamiento de la "nueva izquierda" reivindica, como sostiene Maurice Cranston, al Marx que denuncia la enajenación del hombre y no al Marx economicista. 
Internacional, y las moscovitas y castristas que, a su manera, habían construido un camino nuevo en el proceso del cambio revolucionario en el continente.

La idea de la revolución en marcha o de la revolución como un proceso cuyo final inevitable se imaginaba asociado al triunfo pleno de las mayorías democráticas (básicamente campesinas y obreras) y la construcción del hombre nuevo, desenajenado, es central y justifica el pensamiento y las acciones de muchos de los escritores de la época que ven en la experiencia de Cuba el futuro que le espera a todo el continente.

De hecho, la solidaridad de muchos de los intelectuales-críticos-escritores de entonces se evidencia en manifiestos, tomas de posición y en múltiples formas de apoyo a la Revolución cubana y a su gran aparato de difusión continental que fue ese centro de irradiación política y cultural llamada Casa de las Am éricas. Por todo lo dicho, desde fines de los años cincuenta hasta mediados de los años ochenta en América Latina, el reconocimiento de un intelectual como tal se generaba a partir de un proceso de legitimación que se iniciaba cuando el escritor podía ser identificado como alguien con una filiación y una fe izquierdistas sustentadas en la defensa de Cuba.

Sobre la base de convicciones asumidas a través del discurso de ciertos sociólogos como Wrigth Mills o Paul Baran y filósofos como Sartre, nuestros escritores, en el contexto revolucionario de los años sesenta, estuvieron aptos para intervenir en la escena política. Es el momento en el que asumen esta doble identidad de escritores-intelectuales y se produce su incursión en los espacios públicos precisamente para ganar esa dimensión que el solo ejercicio de la escritura literaria no podía darles. La idea es que los escritores debían contribuir no solo con la obra sino con la propia vida a la transformación de la sociedad y que su papel debía ser central en ese cambio.

Paul Baran, por ejemplo, identificaba al intelectual como alguien capaz de abarcar y comprender la totalidad social, y le asignaba la función de recordar que "las partes, al parecer autónomas, dispares y desarticuladas de la experiencia social bajo el capitalismo -la literatura, el arte, la política, el orden económico, la ciencia, la condición cultural y psíquica del pueblo- pueden ser comprendidas e influidas solamente en la medida en que sean visualizadas como componentes de la totalidad integrante del proceso histórico" (1961:17). Baran, así, reconoce en el intelectual a un agente capaz de "iluminar los obstáculos que impiden un orden más humano y racional”. En él, también, la idea de que "las clases gobernantes consideran al intelectual un agitador, un utópico, un subversivo" es importante.

¿Cómo gana dimensión política la función del escritor-intelectual? se pregunta Baran. Él responde postulando, en principio, que el escritor es un agente incómodo para el poder instituido a través de la estructura de los Estados 
antidemocráticos y que es oponiéndose a ese poder como el escritor justifica su función social. Esta idea, central en los planteamientos de Baran, será decisiva en el discurso "La literatura es fuego" de Vargas Llosa. Lo es también la idea que Carlos Fuentes empieza a difundir en los años sesenta cuando reconoce que la legitimidad ideológica de la literatura solo se da cuando esta se instaura como un discurso de resistencia frente a cualquier tipo de poder. Sin esta resistencia, la literatura dejaba de ser peligrosa y perdía, incluso, su potencia explicativa. Como sostenía Morin, el escritor debía y podía dejar de ser solamente un creador de ficciones para convertirse en un intelectual: " $\mathrm{Si}$ un escritor escribe una novela, decía, es un escritor, pero si además habla de la tortura es un intelectual y su tarea es serlo".

Son estas convicciones las que le dan consistencia y sentido a lo que Bourdieu llama campo intelectual durante los años sesenta y es a partir de ellas que los entonces escritores-intelectuales se dirigirán a sus respectivas sociedades como Vargas Llosa lo hace cuando, en el discurso que titula "La literatura es fuego" se dirige a las sociedades latinoamericanas anunciado el peligro que entraña ese ser anómalo que es el escritor y su práctica, la literatura, entendida como una insurrección permanente ${ }^{2}$.

De esta forma, los escritores se integran, desde el ejercicio de la literatura, a las vanguardias políticas y así justifican su existencia en los procesos revolucionarios como el de Cuba, que había demostrado la importancia que podían llegar a tener las vanguardias intelectuales en el llamado momento de insurrección, decisivo para propiciar las condiciones para la revolución. Vistos así, los intelectuales se integraban a una cadena de eventos importantes colaborando en la construcción de las condiciones subjetivas para la realización de la revolución.

Para Mario Vargas Llosa era clara la distinción entre el intelectual y el creador de ficciones y más claros aún los problemas que podían producirse al no darse la deseada sintonía entre ambas condiciones. En medio de su fe en el socialismo, y cuando es encuestado a mediados de los sesenta sobre el papel del intelectual en los movimientos de liberación concluye con lo siguiente: "Pero entiendo que en el caso del creador se plantea un desgarramiento irremediable, ya que en el creador el elemento determinante no es nunca racional

2 La expresión "insurrección permanente" es empleada por primera vez por Vargas Llosa en marzo de 1966, en un artículo periodístico que publica en Expreso y que titula precisamente “Una insurrección permanente". En él, lo que Vargas Llosa defiende es la absoluta libertad de los escritores para ejercer la crítica dentro de la Revolución o, mejor dicho, asumiendo el compromiso político con ella. Esta libertad revela una de las creencias de la época que Vargas Llosa sostiene mejor que nadie y que es visible en su discurso "La literatura es fuego": la fidelidad a la vocación literaria es anterior a cualquier otra, incluso la política, y ningún escritor puede ser perseguido o encarcelado por ejercer su derecho a la crítica. 
sino espontáneo, incontrolable, esencialmente intuitivo. Y el escritor no puede poner ese elemento al servicio de nada de una manera premeditada. En cierta forma el creador se plantea así una verdadera duplicidad, o por lo menos una terrible tensión: quiere ser fiel a una determinada concepción política y al mismo tiempo necesita ser fiel a su vocación. Si ambas coinciden, perfecto, pero si divergen se plantea la tensión, se produce el desgarramiento. No debemos empero rehuir el desgarramiento; debemos, por el contrario, asumirlo plenamente y de ese mismo desgarramiento hacer literatura, hacer creación. Es una opción difícil, complicada, torturada si se quiere, pero imprescindible" (Vargas Llosa, 1966: 98).

En este contexto de creencias resulta absolutamente coherente que, para Vargas Llosa, el poeta Oquendo de Amat constituya el paradigma del creador y del intelectual en el que se da lo que él llama la coincidencia entre las concepciones políticas y el ejercicio libérrimo y honesto de la literatura. En el furor de la prédica socialista de los años sesenta, la militancia comunista de Oquendo y su azarosa vida como activista político entre obreros y estudiantes (la misma que lo terminaría conduciendo al destierro a Panamá) cumplían con creces lo que podía entenderse como consecuencia política. Oquendo de Amat, era pues, el intelectual comprometido, pero también el creador, el "hechicero consumado de la palabra”, la máxima expresión de la vanguardia poética en el Perú; pero también el hermano comunista, el esclarecido integrante de la vanguardia política.

Por otro lado, Oquendo también respondía a los propósitos de modernización que un escritor como Vargas Llosa, integrante del boom, buscaba a través de sus textos. Recordemos que en Vargas LLosa se da una fuerte influencia de la narrativa europea y norteamericana de principios del siglo XX. De hecho, los del boom están lejos de las formas del arte promovido oficialmente por la unión soviética y por los comisarios del stalinismo y más lejos aún de las paralizantes e ingenuas poéticas del realismo socialista. Pensemos, en este sentido, en el Cortázar parodiando esos modelos y asumiendo en Rayuela los vertiginosos principios del surrealismo libertario.

Era previsible, entonces, que la reflexión en torno a las artes, y a la literatura en particular, se viera afectada por el discurso político dentro del cual el discurso estético debía encontrar su propia pertinencia. Por ello es comprensible que al escritor, ya convertido en un intelectual comprometido, se le asignasen algunas tareas o la resolución de ciertos problemas frente a los cuales debía de asumir una posición políticamente clara, sobre todo por las urgentes demandas (pobreza, ignorancia, subdesarrollo económico) de un contexto como el latinoamericano. 
Un ejemplo de esta preocupación de los críticos literarios por orientar la labor de los novelistas, o de establecer ciertas pautas para la discusión en torno a los problemas del escritor en un contexto revolucionario, nos lo da Ángel Rama, quien en 1964 publica un texto clave: "Diez problemas para el novelista latinoamericano" en la ya famosa revista Casa de las Américas, en un número dedicado a la nueva novela latinoamericana ${ }^{3}$.

El artículo de Rama, que acompaña una nutrida muestra de lo mejor de nuestra narrativa continental, se presenta como una invitación a la reflexión sobre los problemas más acuciantes que atañen a la condición del escritor. En él, Rama comienza por diagnosticar el presente latinoamericano como un "tiempo urgido, desgarrado, contradictorio, como en época de revolución inminente" (1964:3) y a la creación artística como una manifestación de ese presente que es urgente representar. La idea es bastante clara: los novelistas latinoamericanos deben ser plenamente conscientes de las limitaciones que su sociedad les impone para ejercer su oficio y de los efectos que la inserción social de su discurso pueden producir. Además, si se observa bien, a Rama le interesa advertir sobre los desafíos que el ser escritor implica y las responsabilidades que ello conlleva en un continente como el nuestro.

Para los efectos de nuestra indagación, consideramos que es posible y conveniente atender a algunas de las preocupaciones que Rama plantea en este artículo y ligarlas a las que revela Vargas Llosa en su discurso "La literatura es fuego" en tanto el discurso recoge, como ningún otro documento, esas preocupaciones proyectadas desde la conciencia de un escritor que ya ha empezado a desarrollar una irreductible posición crítica en un contexto marcado por el compromiso político con Cuba.

\section{Las bases económicas y la obra artística en "La literatura es fuego"}

Cuando Rama analiza las bases económicas que dinamizan la actividad productiva del continente (1964: 5) dentro de las cuales el escritor latinoamericano realiza su labor, cumple, a la vez, con denunciar una situación insostenible: a los creadores literarios les es prácticamente imposible lograr el ejercicio es-

3 Este número de la revista, el número 26, correspondiente a octubre-noviembre de 1964, es clave en el desarrollo de la difusión de los narradores del "boom" y en la consolidación de un "partido de escritores" en torno a la Revolución cubana. Además del artículo de Rama, que abre la revista, se incluyen adelantos de novela de autores como Carpentier, Cortázar, Onetti, Sábato, Fuentes y Vargas Llosa y se muestra la capacidad crítica de algunos de ellos. Este número tiene una editorial que se titula "Nuestra respuesta" y denuncia las presiones de la OEA para que tres países rompan relaciones con Cuba. La respuesta frente a esa agresión política es la muestra literaria que contiene la revista. 
pecializado de su oficio. En un contexto político caracterizado por la existencia de Estados burgueses interesados en fomentar la formación de intelectuales (abogados, médicos, educadores) útiles a sus proyectos de consolidación histórica, la literatura y los escritores son librados a las irregulares demandas de un mercado de lectores casi inexistente. Bajo estas condiciones los escritores, según Rama, se ven obligados a la realización de tareas reconocidas por un Estado de carácter utilitario o se ven obligados a ejercer solitariamente su oficio.

Este aspecto de la condición del escritor es tratado por Vargas Llosa en su discurso cuando se refiere a la figura del poeta Carlos Oquendo de Amat. Del puneño exalta el extraordinario valor de su obra a pesar de las duras condiciones de sobrevivencia y del implacable celo con que lo castigó la sociedad a lo largo de su vida. Vargas Llosa no encuentra en su obra el "apresuramiento, la improvisación, la falta de tensión y de rigor" que Rama evidenció, incluso, en escritores de la talla de Sarmiento o Martí. No hay en la obra de Oquendo falta de concentración artística ni exceso de inspiración, exceso que terminaba convalidando las tesis románticas de la creación y hacían del escritor un ejecutor apenas consciente de su obra.

En "La literatura es fuego" Vargas Llosa consolida estas ideas al reconocer en Oquendo al poeta que resistió, en la pobreza, los avatares de un sistema en el que el escritor debe "desdoblarse, separar su vocación de su acción diaria, multiplicarse en mil oficios que lo privaban del tiempo necesario para escribir y que a menudo repugnaban a su conciencia y a sus convicciones" (1983:135). Oquendo, por ello, para Vargas Llosa, no cejó, no renunció a su vocación, no se convirtió en otra cosa que no fuera un intelectual y no trabajó sobre la fatiga, como dice Rama citando a un escritor uruguayo, ofreciendo de este modo, solo el remante de su talento, las sobras de su esfuerzo.

En la perspectiva de Vargas Llosa, Oquendo es, pues, un héroe intelectual, alguien que no hipotecó su genio y que no renunció nunca al honesto ejercicio de la literatura, para dejar un ejemplo. Oquendo se constituye, de este modo, en un escritor modelo, aquel que asumió, con todas sus consecuencias, la condición de creador literario en un páramo cultural, en un medio hostil a su oficio y a la literatura. Es cierto que la figura del héroe se construye sobre la base de acciones en las que queda retratado su interés por el otro llegando al sacrificio y a la inmolación de la propia vida. Pues bien, Oquendo consumió su vida ofreciéndola al arte y en esa actitud, que no conoció claudicación posible, se consolidó su heroísmo.

Oquendo, en la mira de Vargas Llosa, podía tener un apellido cortesano, de virrey, pero era un hombre de escasos recursos económicos, "un provinciano hambriento y soñador que, en Lima, vivió en el barrio del Mercado, en una cueva sin luz" (1983:132). La descripción del poeta vanguardista en estos tér- 
minos consigue ahondar en las condiciones de pobreza que le tocó vivir y se constituye en un argumento más de su heroicidad cultural.

Oquendo, no obstante pertenecer a una élite tan exclusiva y excluyente como la de la vanguardia, no pudo dejar de convertirse en un marginal. El ser un "hechicero consumado, un brujo de la palabra, un fulgurante explorador del sueño" no lo libró de su destino fatal, destino trágico que le cobra la vida a aquellos que persisten en la vida respetando su propia dignidad.

\section{Cosmopolitismo y nacionalismo en "La literatura es fuego"}

Oquendo es descrito en el discurso de Vargas Llosa como un "joven que había leído con fervor los primeros escritos de Breton” y cuya obra, Cinco metros de poemas, poseía "una delicadeza visionaria singular". Con estos dos elementos el autor filia a Oquendo al vanguardismo y de esa forma lo inserta dentro del primer círculo con el que opera Rama para determinar la incorporación social del escritor. Nos referimos a "la escuela dentro de la cual se organizan los principios formales, los tratamientos temáticos de seleccionados materiales, las ideas sobre el arte, las tradiciones y jerarquías valorativas" (1964:8) con las cuales el escritor se construye una identidad literaria. Al elegir a Oquendo, Vargas Llosa hace un elección importante porque está eligiendo a un doble marginal, es decir, a un escritor que produce un tipo de producción poética cuyo consumo social es muy limitado y cuya situación estética respecto de la escuela dominante también resulta siendo marginal. El caso de Oquendo se agrava si pensamos que Vargas Llosa lo observa como un provinciano cuya integración a la élite del vanguardismo citadino se realizó de manera problemática, por decir lo menos.

Más importante resulta, sin embargo, entender que Vargas Llosa eligiera a Oquendo sobre lo esencial que resultaba para él, como para los escritores del "boom", relacionarse con una tradición occidental como la vanguardista (si no pensemos en la obra de Cortázar) y reconocer, con la gratitud del caso, la influencia que tuvo la vanguardia en la renovación de la novela en nuestro continente. Para eso le sirve Oquendo, para mostrar la necesaria permeabilidad de una literatura que se quiere moderna y para mostrar, a partir del carácter libérrimo y revolucionario de la vanguardia, la forma en que la literatura debe ejercerse.

Con la elección de Oquendo, además, Vargas Llosa nos muestra la necesidad de dialogar con Occidente y lo imprescindible que es evadir el elitismo sin raíces, ese elitismo que fomenta la simple imitación de los modelos europeos y que Oquendo logra sortear con la originalidad de su obra. 
La fluidez con la que Oquendo transita entre lo local y lo extranjero al filiarse a la vanguardia revela, como sostiene Rama, el poder de las influencias enriquecedoras, algo que escritores como Vargas Llosa sin duda valoraron siempre al declararse enemigos del telurismo literario, del realismo que llamó "primitivo". Con Oquendo queda clara la fusión de las llamadas literaturas autóctonas ${ }^{4}$, en su versión indigenista, con las extranjeras en la consolidación de una literatura nacional.

Al convocar a Oquendo, Vargas Llosa reivindica el carácter universalista de la práctica literaria y vital de un escritor y no olvida la necesaria y mutua fecundación, de las tradiciones nacionales y extranjeras. De este modo sigue a Rama cuando este sostiene que "La literatura existe por vocación universalista, y sin ella, no hay actitud creativa plena” (1964:12).

\section{Sociedad y literatura en "La literatura es fuego"}

Al referirse en "La literatura es fuego" a la sociedad dentro de la cual se gestó la obra de Oquendo de Amat, Vargas Llosa parte de un hecho lamentable que ya había diagnosticado años atrás y que había denunciado en entrevistas y pronunciamientos: las egoístas e insensibles sociedades latinoamericanas terminan liquidando a sus escritores. Citemos: "Es verdad, no todos nuestros escritores han sido probados al extremo de Oquendo de Amat; algunos consiguieron vencer la hostilidad, la indiferencia, el menosprecio de nuestros países por la literatura (...) Es verdad que no todos pudieron ser matados de hambre, de olvido o de ridículo" (1983: 133).

La cita es útil para referir el modo en que el autor construye la figura del héroe intelectual y del espacio en el que este se genera. Oquendo, nos dice Vargas Llosa, lamentablemente fue derrotado por la sociedad y por ello es un ejemplo útil, un caso singular cuya biografía puede decirnos algo, un caso de ensañamiento social contra un poeta extraordinario que persistió, en la medida de sus fuerzas, en aquello que era la razón de su existencia: la creación poética.

Para el autor de "La literatura es fuego", la sociedad latinoamericana le "ofrece al escritor un verdadero festín de razones para ser un insumiso y vivir descontento" (1983:135). La enumeración de defectos es larga y en ella está contenida toda la historia de desaciertos de un continente que es visto como un espacio propicio para la injustica, la ignorancia, la explotación y la miseria.

4 El sustrato andino de la poesía de Oquendo ha sido estudiado con atención por Dorian Espezúa, quien llega a la conclusión, contra posiciones como la de José Varallanos, que Oquendo tuvo la influencia de la vanguardia indigenista. Esta influencia sería visible en una sensibilidad híbrida, heterogénea o transcultural, visible en un conjunto de dicotomías (por ejemplo, campo-ciudad) presentes en algunos de los textos de los 5 metros de poemas. 
Oquendo es un paradigma, una cima inalcanzable que sirve a Vargas Llosa de ejemplo para que todas las burguesías indolentes del continente reconozcan en él al verdadero creador, al puro, al poeta, a aquel que puede morir por sus ideales. En consecuencia, Oquendo es utilizado para demostrar lo insensible que pueden ser nuestras sociedades frente al arte y a la literatura.

Vargas Llosa denuncia, a través de Oquendo, a las burguesías latino-americanas debido a su ineptitud, ruindad e injusticia en el campo cultural, y al hacerlo las hace responsables de la muerte del poeta. Las denuncia en tanto las encuentra responsables del analfabetismo real y del funcional, y de la indiferencia frente a la literatura, responsables de la inexistencia de editores, de lectores y de un espacio para el desarrollo de la vocación del escritor.

Sumido en el infierno del silencio y de la incuria de la sociedad, el escritor que representa Oquendo para Vargas Llosa es el escritor de vocación, el "hombre que libraba batallas sabiendo desde un principio que sería vencido" (1983:133), el hombre que en medio de su marginalidad se empeñó "contra toda razón”, en ejercer un oficio que en la circunstancia latinoamericana resultaba casi irreal". Visto así, Oquendo suma otra característica a su condición de héroe intelectual: el de ser un luchador de causas perdidas de antemano, el noble que libra batallas que considera justas al margen de la posibilidad de poder ganarlas.

Oquendo, pues, para Vargas Llosa, sufrió un clima de absoluta hostilidad social, padeció la carencia de lectores interesados y dispuestos a invertir en cultura. En su caso, además, tuvo que soportar la hostilidad de aquellos contrarios a las prácticas y modos empleados por los vanguardistas quienes combatieron, precisamente, los modos burgueses de pensamiento. Fue visto, en suma, como un "loco benigno" sin espacio ni influencia social, pero al que había que separar, depurar de la sociedad.

Sin un público lector en el Perú, a pesar de la existencia de una burguesía y de ciertas capas medias interesadas en la literatura, Oquendo se vio obligado a salir del Perú, inflamado por sus ideas libertarias y por la esperanza de encontrar un mejor espacio para el desarrollo de su vocación y de sus ideales de justicia.

El tratamiento del horizonte social en el discurso "La literatura es fuego" le sirve a Vargas Llosa, finalmente, para la formulación de una advertencia que se genera en un contexto en el que, al parecer, la situación del escritor empieza a modificarse por el cambio de actitud de las sociedades para con ellos. No hay que olvidar que, después de todo, Vargas Llosa está siendo reconocido con el mayor premio literario de la historia del continente americano. Esa advertencia es contra aquellas sociedades que piensan que pueden, ahora, asimilar al escritor después de haberlo reconocido con la profesionalización de su oficio, “integrarlo, conferirle una especie de estatuto oficial” (1983: 134). Así, pues, 
Vargas Llosa concluye con la idea de que las sociedades solo pueden esperar del escritor "un torrente de agresiones", una acerba crítica al poder en el que se sustentan, ser unos insurrectos permanentes.

\section{La figura del escritor y el "fuego" de la literatura}

La figura de escritor construida por Vargas Llosa en su discurso es la del hombre que protesta, critica y lucha contra las "deficiencias, vacíos y escorias que lo rodean" y cuya arma, la literatura, es el fuego que destruye y purifica, que extermina y permite el nacimiento de lo nuevo. Reconoce a la contradicción como el dinamizador de la polémica y extiende el oficio del escritor al del permanente perturbador social.

Vargas Llosa retoma la figura del escritor como la del sujeto descontento e insatisfecho cuya problemática relación con la realidad lo ha empujado a cometer el "ambicioso desatino de inventar realidades verbales" (1983:134). Aquí habría que anotar que esta concepción no deja de ser romántica al asignarle al escritor una tarea, en algún sentido, absurda e imposible. Considerar desatinada su labor, aunque la referencia sea hiperbólica, contradice el poder simbólico del lenguaje y la influencia que, finalmente, a través del arte, tiene en los seres humanos.

Pasado el tiempo, y sin caer en ningún anacronismo, pareciera que Vargas Llosa determina en su discurso la responsabilidad de escritor a partir de las demandas de un campo intelectual que espera de él una postura radical. Su concepción del ejercicio de la literatura y de la vocación como una insurrección permanente pretende ser un sucedáneo del activismo propiamente revolucionario de la época y proyecta la imagen de un escritor militante, pero también la de un escritor que milita en las líneas del fuego crítico que puede ejercerse desde la literatura. Por ello no es gratuita la elección de Oquendo, cuya militancia literaria y política, probada con su propia inmolación, representaba, precisamente, esa imagen en la que Vargas Llosa quería verse reflejado.

En el discurso "La literatura es fuego" queda planteada la idea de que, incluso, en el contexto del triunfo revolucionario, la tarea del escritor es la del censor, pero también la del analista. Olvidar este papel supone una traición a los principales valores que puede ostentar un creador de ficciones, esos valores que, alrededor del eje de la libertad, le permiten, como un privilegiado, advertir la complejidad de los hechos humanos y entender que llegar a la verdad siempre supone un camino de sacrificio. Estos valores, centrales en el pensamiento de la nueva izquierda, serán centrales en el discurso de Caracas y cuestionan la línea única, la sumisión a un pensamiento central y, más bien, reivindican la figura individual del escritor. 
Las creencias de Vargas Llosa sobre el poder regenerador o mejorador de la literatura y la utilidad que esta puede tener en la vida del hombre son retomadas en este discurso. Es destacable la fe con la que expresa este convencimiento que, de hecho, no ha decaído hasta hoy: "La literatura contribuye al perfeccionamiento humano impidiendo el marasmo espiritual, la autosatisfacción, el inmovilismo, la parálisis humana, el reblandecimiento intelectual o moral. Su misión es agitar, inquietar, alarmar, mantener a los hombres en una constante insatisfacción de sí mismos: su función es estimular sin tregua la voluntad de cambio y de mejora, aun cuando para ello deba emplear las armas más hirientes" (1983:135).

Cuando Vargas Llosa sostiene que "en el dominio de la literatura la violencia es una prueba de amor" (135), está reconociéndole a la literatura una característica central que en los años sesenta también afectaba al discurso político pues no había posibilidad de cambio social si no se operaba violentamente contra las injustas estructuras de dominación social. Vargas Llosa vincula literatura y violencia no solo en su obra novelística, sino en sus propias reflexiones sobre la naturaleza de la literatura y si lo hace en el discurso de Caracas es para mostrar lo implacable que pueden y deben ser los escritores contra su propio país.

El fuego de la literatura es, pues, una metáfora que ilustra la regeneración que el fuego lleva a cabo cuando destruye algo impuro y permite el nacimiento de lo incontaminado, de lo puro. Es ese fuego que se viabiliza a través de "ironías, de sátiras, que irán de lo adjetivo a lo esencial, de lo pasajero a lo permanente, del vértice de la base a la pirámide social” (1983:134) y que serán proferidas por el escritor en cualquier circunstancia y sin mediar autorización o diálogo posible.

Finalmente, el fuego de la literatura es configurado como ese fuego que es el ardor con que se excitan las pasiones humanas, como el amor y como el odio que, en el marco que propone el discurso, se constituyen en sentimientos o emociones sin los cuales el escritor estaría imposibilitado de representar eficientemente la realidad.

\section{Oquendo: el poeta mártir}

La figura del poeta mártir se construye a través de la sentida evocación de la figura del poeta Oquendo de Amat, a través de la reconstrucción imaginada de una vida que Vargas Llosa siente próxima y que es necesario recuperar del injusto olvido en un momento (el del esplendor de la revolución, el de la lucha del Che Guevara quien aún no había sido ejecutado) en que se hace necesario convivir con ese recuerdo y exaltarlo. 
Contra la muerte, que en el caso de Oquendo es el olvido de su imagen y de su obra, Vargas Llosa convoca su recuerdo y lo instala en medio de una celebración (la entrega del premio) con el propósito de que opere activamente sobre un presente conflictivo y sobre las concepciones morales de todos aquellos que lo están escuchando en la ceremonia de premiación.

Oquendo de Amat es, en palabras de Vargas Llosa, un ejemplo, quizá el mejor, de la forma en que un creador debe asumir su vocación, el mejor ejemplo de quien nunca la traicionó, "sirviéndola a medias y a escondidas, sin porfía y sin rigor (1983: 134). Oquendo es elegido por Vargas Llosa a partir de una necesidad: la de mostrar a un poeta cuya inmolación por el arte y entereza moral pueda inmunizarlo de cualquier sospecha, de cualquier posibilidad de ser identificado como cómplice de un gobierno (el de derechas de Leoni en Venezuela) que lo premiaba a través de su Instituto Nacional de Cultura y Bellas Artes.

Por ello, la representación de la imagen de poeta-mártir, construido por el novelista peruano funcionará en el discurso de premiación como un operador moral, como una defensa contra quienes en ese momento están pensando que Vargas Llosa ha claudicado aceptando el Premio Rómulo Gallegos. Esto puede comprenderse si atendemos, como dijimos, a la naturaleza del contexto político venezolano del momento, viciado por el autoritarismo de un gobierno que, además, y de manera grave, había roto relaciones con Cuba.

En su discurso, Vargas Llosa habla de "el fantasma silencioso de Oquendo instalado aquí, a mi costado" y de esa forma, al convocar su recuerdo, lo convierte en una presencia poderosa, arrancándolo por unos momentos del mundo de los muertos. Oquendo es una presencia heroica que satura moralmente el espacio en que es leído el discurso y se hace presente para cumplir con una función que el éxito le impide cumplir al propio Vargas Llosa. Quizá movido por una conciencia que se debate entre la culpabilidad que supone no haber sufrido los embates sociales como el Oquendo que reconstruyen sus palabras y el deseo de ser reconocido continentalmente, a Vargas Llosa le parece imprescindible asociarse a su recuerdo, pero sobre todo a su significación.

El discurso nos refiere a un Oquendo en tres momentos de su existencia. Nos lo muestra en vida, en el momento de su muerte y después de muerto. La síntesis vital no resulta nada halaguieña. La vida de Oquendo no puede resumir más desolación, más infortunio, más desgracia. La mención a su "nombre sonoro y cortesano, de virrey", es utilizada para demostrar que, a pesar de tener un apellido con esa estirpe colonial, las condiciones sociales en las que se desarrolló no le fueron favorables. La mención no hace sino mostrar que Oquendo, siendo de alguna manera, por cierto bastante lejana, parte de esa burguesía parasitaria de Puno, decidió exiliarse en su propio mundo. 
"Hechicero consumado, brujo de la palabra, osado arquitecto de imágenes, fulgurante explorador del sueño", son algunas de las hermosas calificaciones que Vargas Llosa emplea para valorar el quehacer poético de Oquendo. En ellas observamos al autor calificando a la poesía como un oficio de iniciados, un saber que supone la posesión de algo privilegiado, un saber que se comparte porque se es uno más de la cofradía que posee la llave del misterio de la creación.

Vinculándolo con aquella escuela que sintonizaba con su teoría de los demonios, es decir, con el surrealismo, Vargas Llosa se siente cómodo con Oquendo porque en el fondo no contradice sus creencias literarias y porque lo considera su par; porque, como él, se entregó, en la creación, al sueño, a lo irracional, a la sinrazón. "Un joven que había leído con fervor los primeros escritos de Breton" dice para referirse a Oquendo, y con esas palabras confirma la fuerza avasallante del surrealismo que había inspirado la violencia y la verdad de otro desafortunado que admiró: César Moro.

¿Cuál fue el precio que Oquendo tuvo que pagar para ser fiel a sus creencias y a su oficio? Según Vargas Llosa, la soledad, la pobreza, la oscuridad, esa terca infelicidad que lo persiguió hasta después de muerto, ese conjunto de circunstancias que lo "probaron" llevándolo hasta los extremos de la destrucción.

Después de ubicar a Oquendo en ese extremo, Vargas Llosa se refiere al "destino sombrío" de los escritores en América Latina, a la irremediable condición del escritor en un continente que no lo valora y que además lo margina. La diagnosis no puede ser más desalentadora.

Para Vargas Llosa, Oquendo no pudo vencer la hostilidad, la indiferencia, el menosprecio de la burguesía por la literatura. No las pudo vencer porque "vivió y escribió en condiciones excepcionalmente difíciles", pero sobre todo porque "vivió rodeado de gente que en su mayoría no sabía leer o no podía comprar libros o no le deba la gana de leer". Oquendo escribió en condiciones adversas no solo porque no existía entre nosotros una sociedad de lectores o no estaba preparada para acoger su obra, sino porque esa sociedad no podía materialmente otorgarle un lugar. Y no podía porque esa sociedad había sido incapaz de producir editores interesados en la poesía, porque esa sociedad no había generado una clase intelectual capaz de hacer de la poesía un arte en el cual esa sociedad pudiese verse a sí misma. ¿Qué valor podía tener, entonces, un poeta y, más aun, su poesía?

En un universo clausurado, en un país en "donde la injusticia es ley", en un país considerado como un "paraíso de ignorancia, de explotación, de desigualdades cegadoras, de miseria, de alineación económica, cultural y moral”, era, sin duda alguna, imposible llegar a ser un escritor.

Este es el momento en el que Vargas Llosa realiza, en su discurso, esa inflexión que abre las compuertas de ese nuevo mundo que lo tiene fascinado: 
Cuba, mundo al que presenta como el ideal al que hay que acercarse, como el único que ha sabido acoger en su seno a los escritores.

\section{La imagen de la Revolución cubana en "La literatura es fuego"}

La revolución cubana generó en los escritores del "boom" dos demandas: la primera se articuló a la necesidad de responder a las preguntas de un público joven que empezaba, desde su acceso a las universidades, a reflexionar sobre la identidad y el destino de América Latina; la segunda se articuló a la preocupación por el modo de consolidar lo que Cuba había empezado a lograr algunos años antes con el triunfo de la Revolución. Estas dos demandas, que el campo intelectual hispanoamericano procesa a través de sus críticos y escritores, configuran el perfil del llamado intelectual comprometido de izquierda y le otorga sentido a su papel como tal. Sumemos a esto el impulso o la voluntad en muchos de los intelectuales de la época de llevar a la realidad el cambio a partir de una concepción socialista del mundo en la que los países del continente americano establecían o desarrollaban lazos de hermandad cuya naturaleza los convertía en parte de una sola patria, la latinoamericana.

Vargas Llosa, como la mayoría de escritores de su generación, participó de ese "partido intelectual" alrededor de las expectativas despertadas por la revolución cubana que ya a mediados de los sesenta se había convertido "en el epicentro de la formación de la familia intelectual latinoamericana" (Gilman, 2003: 113), al punto que "cumplió, además, una función de referencia obligada en las intervenciones de muchos intelectuales" (113). En el texto titulado "Crónica de Cuba" ${ }^{5}$ publicado en 1967, año del discurso "La literatura es fuego", Vargas Llosa escribe lo siguiente: "Hay que recorrer un complicado camino para llegar a Cuba. El bloqueo que desde años impuso Washington a la isla, no tenía solo como objetivo privarlas de las importaciones que, hasta la revolución la habían hecho sobrevivir, sino también y sobre todo, ponerla en cuarentena política y cultural, expulsarla de la familia latinoamericana, excluirla como un leproso para evitar el contagio. El bloqueo que, en el campo material, ha afectado, sin duda, seriamente a la economía cubana (aunque no ha conseguido asfixiarla, como esperaban los hombres de la OEA) en el dominio cultural ha resultado un clamoroso fracaso: se trata de algo que puede enorgullecer a los intelectuales latinoamericanos. Ni las dificultades que presenta el viaje a Cuba desde el punto de vista material (México es el único país que mantiene vuelos

5 Esta crónica fue publicada en el libro homenaje Cuba, una revolución en marcha editado por Ruedo Ibérico en 1967. Puede encontrarse en la sección final titulada “Testimonios”. Este libro es un voluminoso suplemento de más de quinientas páginas que recoge discursos, poemas y crónicas a favor de Cuba, escritos por intelectuales como Juan Goytisolo, Mario Vargas Llosa, Julio Cortázar, entre otros. 
hacia La Habana, pero el latinoamericano que sale por allí, además de ser fotografiado y fichado como un indeseable, está prohibido de retornar a su país por la misma vía), el absurdo periplo que por ejemplo obliga a un venezolano a viajar hasta Praga o Madrid para llegar a La Habana, ni las represalias que muchos gobiernos latinoamericanos toman contra los ciudadanos que violan la interdicción (que figura en los pasaportes, como en el caso del Perú) de visitar el país apestado, han impedido a los artistas y escritores de este Continente llegar a la isla, comprobar, con sus propios ojos, lo que ocurre allí y dialogar o discutir con sus colegas cubanos" (1967:509).

Las referencias que Vargas Llosa hace en esta crónica al fracaso del bloqueo cultural impuesto a Cuba como consecuencia del bloqueo económico, nos sirven para medir el entusiasmo con que los intelectuales vivían la revolución y el apoyo que le proporcionaban a pesar de los obstáculos para llegar a la isla. Ya en 1962, en un texto que tituló "Crónica de la revolución", Vargas Llosa mostraba una fe y un entusiasmo exultantes por lo que sucedía en Cuba, los mismos que hacia 1967 no habían decaído en absoluto a pesar del caso de los escritores rusos Andrei Siniavski y Yuri Daniel quienes, en 1966, fueron enjuiciados y condenados por criticar y satirizar las formas de ejercicio político en la URSS y a pesar del encarcelamiento de Alexander Solzhenitsin, quien había lanzado críticas feroces contra la política cultural de las autoridades soviéticas.

En esos años Vargas Llosa se refería, debido a esos casos, a la actividad literaria como una insurrección permanente, criticando las políticas de la Unión Soviética y notando que los escritores no debían renunciar jamás a la libertad de protestar, ni al hecho de ser los "profesionales del descontento, los perturbadores conscientes o inconscientes de la sociedad, los rebeldes con causa, los insurrectos irredentos del mundo, los insoportables abogados del diablo" (1983: 136). En ese contexto, el discurso "La literatura es fuego", cobra su verdadero sentido, pues reclama, en un sentido amplio, el ejercicio de esa libertad.

El hecho de que Vargas Llosa reivindicase a Cuba en un contexto como la Venezuela de Leoni, es un acto de valentía. Es cierto que matizado por el propósito de "limpiarse moralmente" de cualquier posible simpatía o compromiso con los gobiernos de derecha y más específicamente con el gobierno venezolano, pero, desde todo punto de vista, honesto. El escritor peruano acepta el premio Rómulo Gallegos de novela con una condición: que la aceptación no suponga ni la más leve sombra de compromiso ideológico, político ni estético con el Instituto Nacional de Cultura y Bellas Artes de Venezuela.

Vargas Llosa, así, se acerca al final de su discurso avizorando, en el horizonte latinoamericano, la realización de lo que para él ya es una realidad en Cuba. Él lo dirá así: "Pero dentro de diez, veinte o cincuenta años habrá llegado a 
todos nuestros países, como ahora a Cuba, la hora de la justicia social y América Latina entera se habrá emancipado del imperio que la saquea, de las castas que explotan, de las fuerzas que hoy la ofenden y reprimen. Yo quiero que esa hora llegue cuanto antes y que América Latina ingrese de una vez por todas en la dignidad y en la vida moderna, que el socialismo nos libere de nuestro anacronismo y nuestro horror" (1983:135).

Es importante notar, en estas palabras prospectivas y utópicas, la idea de la inevitabilidad del triunfo del socialismo, muy común en la época, triunfo que equivalía a la recuperación de nuestra dignidad, por un lado, y, por otro, el ingreso a la modernidad que solo es vista en el discurso como un movimiento emancipador, como un momento que se aleja del pasado, al que busca cancelar radicalmente.

Marcado el compromiso con el socialismo y ajustada la fe con Cuba, puede observarse que la sacralización de la figura de Oquendo le sirve a Vargas Llosa para reprocharle a las parásitas burguesías latinoamericanas toda su indiferencia con los escritores y el arte y, simultáneamente, para edificar la imagen del escritor convertido ya en un héroe intelectual, cuya devoción por el ejercicio crítico de la literatura debe conducirlo inevitablemente a una insurrección permanente, a una inconformidad sustancial. Ese es el sentido final del discurso "La literatura es fuego", esto es, sostener que un escritor jamás podrá desarrollarse en ámbitos reñidos con la justicia y que debe serle fiel a su vocación a pesar de lo injusto que pueda ser la sociedad con él.

La filiación vargasllosiana a una fe en la que el modelo revolucionario de sociedad cubana es el paradigma se ajusta a las esperanzas de los escritores intelectuales de izquierda de la época. Que el futuro contradijera los valores que Vargas Llosa defendía entonces con respecto al régimen de Castro obligándolo a romper con la Revolución cubana (en realidad pasarían sólo cuatro años para que explotara el Caso Padilla) es, desde luego, una situación que no toca a Oquendo ni a su imagen imperecedera. Su imagen y su recuerdo construidos en "La literatura es fuego" seguirán siendo los del poeta mártir, los de un hombre entregado a la búsqueda de la justicia y al honesto amor a la literatura.

\section{Referencias bibliográficas}

BARAN, Paul (1961) "El compromiso del intelectual” en Revista Casa de las Américas, 7; pp. 14-21.

BOURDIEU, Pierre (1995) Las reglas del arte. Génesis y estructura del campo literario. Barcelona: Anagrama.

CRANSTON, Maurice (1972) La nueva izquierda. Seis ensayos críticos. México: Editorial Diana. GILMAN, Claudia (2003) Entre la pluma y el fusil. Debates y dilemas del escritor revolucionario en América Latina. Buenos Aires: Siglo veintiuno editores Argentina. 
RAMA, Ángel (1964) "Diez problemas para el novelista latinoamericano" en Casa de las Américas, 26; pp. 3-43.

VAN DIJK, Teun (2006) Ideología. Una aproximación multidisciplinaria. Sevilla: Gedisa.

VARGAS LLOSA, Mario (1966) "Respuesta a la encuesta "El papel del intelectual en los movimientos de liberación nacional” en Revista Casa de las Américas, 35; pp. 97-98.

VARGAS LLOSA, Mario (1967) "Crónica de Cuba” en Cuba, una revolución en marcha (selección, montaje y notas de Francisco Fernández-Santos y José Martínez). Paris, Ediciones Ruedo Ibérico; pp. 508-510.

VARGAS LLOSA, Mario (1983) "La literatura es fuego" en Contra viento y marea (19621982). Barcelona, Seix Barral; pp. 132-137. 